\title{
Implementing telemedicine technologies through an unlearning context in a homecare setting*
}

\begin{abstract}
Despite the opportunities the health sector will offer as a result of the design and development of a technology infrastructure, the fact is that hospitals have been slow to adopt telemedicine technologies, largely because very few organisations are prepared to face this challenge. A possible explanation for the efficiency and effectiveness gaps of services provided by Hospital in the Home Units $\left(\mathrm{HHU}_{\mathrm{S}}\right)$ may relate to the advantages and disadvantages of the knowledge processes that these units exhibit as a result of their different structural properties. This paper investigates the approaches that HHUS have used to update the knowledge of physicians and their members' knowledge of technology and relates them to an unlearning context and improvement in the quality of health services. These relationships are examined through an empirical investigation of 55 doctors and 62 nurses belonging to $44 \mathrm{HHU}_{\mathrm{s}}$. The research findings suggest that the key benefits of an unlearning context in HHUs are clear. It enables them to identify and replace poor practices and also avoids the reinvention of the wheel, it enables cost reduction by minimising unnecessary work caused by the use of poor methods, and it enables improvements adopting new telemedicine technologies.
\end{abstract}

Keywords: unlearning context, telemedicine technologies and quality of service.

\footnotetext{
* The dates in this research were taken from a research programme supported by the Spanish Ministry of Education (REF: ECO2008-0641-C02-02), entitled: 'Strategic Scientific Knowledge Management in the Sanitary Industry: An Application in Home Care Units'.
} 


\section{Introduction}

The Spanish healthcare system is recognised as one of the best public health programmes in the world, it provides health services to all Spanish residents, regardless of their socioeconomic status or participation in the formal social security network (Navarro, 2000). In addition, since the system is based on the universal provision of healthcare, nonresidents and tourists (and even people living in the country illegally) are also provided with treatment. The Spanish healthcare system has undergone important changes, particularly in the development of new hospital services. The Hospital-in-the-Home Unit (HHU) is an innovation that delivers acute hospital services to appropriate patients in their own homes (Ridao et al., 1997). The key benefits of the use of technologies in HHUs are clear. It enables them to identify and replace poor practices and also avoids the reinvention of the wheel (e.g. by minimising unnecessary work caused by the use of ineffective methods), reduces costs through better productivity and efficiency (improving services to patients) and increases profitability (Thouin et al., 2008).

However, despite the opportunities the health sector will offer as a result of the design and development of a technology infrastructure, the fact is that hospitals have been slow to adopt information technology (Menachemi et al., 2008) largely because very few organisations are prepared to face this challenge (Brakensiek, 2002). For example, several state members of the European Union have already established the failure in the application of certain technologies in their health systems. A possible explanation for this would be that when care services are provided in the home, an important factor to consider involves the effort required to unlearn the practices that involve the technology that the practitioner is used to using in the hospital setting. This is often replaced with new (or different) technology used to support practices associated with the provision of care services in the home (i.e. telemedicine) (Starbuck, 1996).

It should be noted, however, that implementing and using new technologies frequently generates internal problems when there is conflict or lack of coherence with current knowledge structures. Such situations arise as a result of differences in terms of, for example, the beliefs, habits and things individuals take for granted which underpin existing knowledge structures and those associated with the new technology (Wilson, 1988). Hence, it can be argued that the presence of an internal context that fosters the replacement of old knowledge is likely to be essential if HHUS are to implement and use new technologies (i.e. telemedicine). To this end, this paper proposes an unlearning context to enable the implementation of technologies. At its heart, this context facilitates the reorientation of organisational values, norms and/or behaviours by changing cognitive structures (Rushmer \& Davies, 2004), mental models (Day \& Nedungandi, 1994), dominant logics (Bettis \& Prahalad, 1995) and core assumptions that guide behaviour (Shaw \& Perkins, 1991). Thus, the contribution of this context, which we refer to as an 'unlearning context', is related to its ability to prepare the ground for the creation of new knowledge and the utilisation of new technologies (Rushmer \& Davies, 2004).

There is no empirical evidence, particularly in relation to $\mathrm{HHU}_{\mathrm{S}}$, to support the concept of an unlearning context and how it relates to technology. In this paper we test our postulated hypotheses about such relationships and the unlearning context, as well as the improvement of the quality of health services. Below, we provide an overview of current research literature addressing unlearning and related concepts, including the potential 
factors that may enable unlearning. The methodology employed to construct the questionnaire and the details of the sample are presented in Section 3, whilst the results from the hypothesis tests follow in Section 4. Finally, the results are discussed in Section 5.

\section{Conceptual framework}

Telemedicine technology can be viewed as a telecommunications technology to facilitate clinical care between participants who are physically separated (Brecht \& Barrett, 1998). The utilisation of telemedicine not only enables an enhanced quality of service and value, but also multi-functional and inter-organisational communication (Chaudhry et al., 2006). Therefore, telemedicine technology can be viewed as both computer hardware and software that deals with the storage, retrieval, sharing, and use of health care information, data, and knowledge for communication and decision making" (Brailer \& Thompson, 2004). In this regard, Bhatt, Gupta and Kitchens (2005) identify certain types of groupware that help to capture, store, and manipulate information and certain aspects of the knowledge management process that would be significantly associated with each other (e.g. email or mailing lists).

The growth of telemedicine has exposed many opportunities for HHUS (Lockamy \& Smith, 2009), in terms of their ability to communicate and collaborate with colleagues, patients and carers while the patient is at home. In a hospital homecare setting where the geographical location of a HHU has a major impact on its operations and profitability, telemedicine technologies help HHUs to enhance patient satisfaction and improve the service experience, as well as provide a means to access information that would otherwise require contact with the hospital's staff. As Harrington and Guimaraes (2005) noted, through telemedicine technologies, users can consider the advantages or disadvantages of many alternative solutions (e.g. increased flexibility, better control over processes and saved time). This, in turn, facilitates the easy transcription of relevant information and enables the users to make the appropriate decisions (Sorensen $\&$ Lundh-Snis, 2001). Therefore, telemedicine tools do not only open chances to convert knowledge into machine-readable forms and store them for future use, but they also help to build trust and rapport with users by permitting them to understand and censor new products and services (Morikawa, 2004). Such tools for face-to-face consultations include among others, video conference, mobile, satellite communication and nurse-led teledermatology (Tulu, Chatterjee \& Maheshwari, 2007).

The relationship between telemedicine technology and quality of service has received considerable attention in literature over the years. Regarding this, Barlow et al. (2007) have reported that although almost 9000 studies reporting on telecare trials and pilot projects have been published in scientific journals, very little strong conclusive evidence has emerged. For example, Whitten and Adams (2003) reported that considerable investments in telemedicine technologies have failed to boost performance. Likewise, Whitten and Adams (2003) found that telemedicine technologies are not isolated, but located within larger health organisations, while Gagnon et al. (2006) indicated the importance of investigating the context in which telemedicine technologies exist prior to implementation. In summary, empirical studies indicate mixed support for the hypothesis that telemedicine technology has a direct effect on performance perceived. 
In this paper, we have followed the suggestion of Mort, May and Williams, (2003) that telemedicine can reduce the duplication of services and overhead costs of providing care. We propose that telemedicine technology allows patients to gain a much deeper insight and to make more informed decisions. As Mort et al. (2003) point out; telemedicine technologies help to reduce the isolation of patients by facilitating peer contact for both practitioner consultations and continuing education. For example, when patients visit a website, they are in a powerful position because they can exercise some control over the data and information that they provide about themselves and, indeed, decide whether to engage in the relationship in the first place. They also allow the HHU to deal with patients systematically (Lockamy \& Smith, 2009), which in turn leads to improved patient service levels and a higher level of perceived quality (Asubonteng et al., 1996). As Barlow and Hendy (2009) noted, the main beneficiaries of telecare are patients and family carers, through the provision of independence, security, confidence, quality of life, and the ability to stay in one's own home. The hypothesis we propose under this framework is:

\section{$H_{1}$ : Adoption of telemedicine technology is positively associated with perceived quality of service}

For all of the benefits provided by telemedicine technologies, there are still barriers to its use. In this vein, Stanberry (2000) argues that budget constraints, insufficient physician acceptance, and fear of the impact on the health care system are a few barriers encountered by health care organizations that have implemented telemedicine technologies. This means that although telemedicine can be a very effective tool to fulfil a HHU's objectives, there are many reasons for failure when implementing telemedicine in and across homecare units. One of them relates to the confidentiality of patient information (Cegarra \& Cepeda, 2010), another to the fact that telemedicine networks introduce new ways of working at all levels of a hospital; after all, the paper records in use today have co-evolved with working practices over many years (Winthereik \& Bansler, 2007). Therefore, successful technology implementation is difficult to achieve, because the homecare setting is diverse, continually evolving, and communication media, documentation standards, incentive structures and homecare practices are interrelated and fit together in complex and subtle ways (Berg, 2001). With respect to this issue, practitioners, technology designers and hospital managers often underestimate the time and effort it takes to successfully adapt and incorporate a new technology into the existing network of people, practices, terminologies and information and communication technologies in the hospital environment. This may result in physicians' reluctance to embrace the use of telemedicine technology (Lapointe \& Rivard, 2005).

The considerations above also imply that all of the individual practitioner's knowledge needs to be reviewed and updated where appropriate when they transition from providing care services with or without modern technologies. A failure to do this will mean that old logics and routines about how the patient must be treated and what is possible and what is not possible will continue to be used both in an expected and unexpected fashion. As Starbuck (1996) noted, using a new technology typically requires a change in people's knowledge, habits and routines and this requires that they forget old knowledge, habits and routines and replace them with new ones. Bearing in mind the tensions when implementing and using new technologies and current knowledge structures for $\mathrm{HHU}_{\mathrm{S}}$, it is possible to use the unlearning context as a 
framework to manage knowledge and achieve an appropriate balance between implementing and using new technologies and current knowledge structures (Akgün et al., 2007; Cegarra \& Sanchez, 2008). In order to do this, it is necessary to consider that forgetting takes place at the individual level because organisations themselves cannot forget (De Holan \& Phillips, 2004). Unlearning at the organisational level is a relearning process where new information structures have to replace old ones (Nonaka \& Takeuchi, 1995). As Akgün et al. (2007) indicate, organisational unlearning or relearning is operationalised through changes of processes and routines in the organisation. In order to enable the forgetting and relearning processes, the unlearning context and its different sub-dimensions are frequently cited as antecedents for the elimination of old logics at the individual level and making room for new ones to occur at the organisational level (Akgün et al., 2007; Cegarra \& Sanchez, 2008). Cegarra and Sanchez (2008) suggest the unlearning context can be measured with three subdimensions:

a) The examination of lens fitting. This refers to an interruption of the employees' habitual, comfortable state of being and it is through such a framework that individuals at an organisation will have access to new perceptions.

b) The framework for changing individual habits. This refers to the challenge of inhibiting wrong habits when an individual has not only understood the new idea but is quite motivated to make the change.

c) The framework for consolidating emergent understandings. This refers to the organisational process that can enable employees to apply their talents by implementing new mental models based on adaptation to new knowledge structures.

Unlearning in health care is essential if HHU members are to tackle a challenging quality of care. An unlearning context provides an environment that supports the balance between technology knowledge and current knowledge structures when this proves necessary. It is through such a context that members of an organisation will identify outdated systems (procedures and structural and cultural artefacts) by introducing new approaches, which results in improved services (Rushmer \& Davies, 2004). This framework enables and encourages individuals to make their own judgment about how to divide their time between conflicting demands for alignment and adaptability and it is through such a context that members of an HHU will introduce new approaches resulting in creative solutions (Jones-Devitt \& Smith, 2007). Therefore, the following hypothesis is proposed:

\section{$\mathrm{H}_{2}$ : The unlearning context is positively associated with the adoption of telemedicine technology}

In order to ensure the research can be generalised, it is important to add control variables to the conceptual framework so that the effects of the unlearning context on telemedicine technology are independent of the HHU's focus on unit performance. Thus, in this paper we have included the HHU's diversity as a control variable. The term "HHU diversity" (HD) refers to the degree to which a social unit is heterogeneous with regards to its labour attributes. Past research has suggested there are two major individual labour attributes, which influence how an organisation functions; these include: (1) gender; and (2) functional background (Church \& Zikic, 2004). With respect to this issue, literature from the late 1980s points to more positive attitudes 
towards computer technology among males (e.g. Arch \& Cummins, 1989). Furthermore, traditional sociological studies of the doctor-nurse relationship describe its patriarchal nature (Dingwall \& McIntosh, 1978), understood in terms of sexual stereotypes, with gender assignations of nurturing and passivity to the female role, and decisiveness and competitiveness to the male role (Savage, 1987). Thus, the practitioner's background and gender may be related to the diversity of the HHU.

\section{$H_{3}$ : The diversity of the HHU is positively associated with the adoption of telemedicine technology}

We group our hypotheses in the next model, represented in Figure 1

$$
\text { Insert Figure } 1 \text { about here }
$$

\section{Method}

\subsection{Data collection}

In order to compare the hypotheses above, home care units (HHU) in Spain were considered. The Hospital-in-the-Home Unit is an ideal platform to learn, because two or more individuals (e.g. patients, carers, doctors and nurses) are working together with different resources and complementary capacities, which are learning facilitator factors (Fenwick, 2007). In practical terms, this has sown the seed for knowledge to be made available and for Hospital-in-the-Home Unit members to be actively directed towards the patient in the form of strategic competence mapping, development and utilisation.

The Hospital-in-the-Home sector is an appropriate setting for an investigation into the unlearning context and its impact on adoption of telemedicine technologies and on quality of service. This is mainly because these units provide 'face-to-face' interaction, allowing the exchange of information to be inserted into the social context of the patients, which by its tacit character is more difficult to imitate. This means constantly searching for new ways to improve homecare services, developing new offerings and introducing improved working methods, but they will only occur if practitioners, carers and patients work together to share individual expertise and create organisational knowledge (Montalto, 1996). Consequently, HHUs are highly motivated to introduce relationships with carers and patients to change roles and expand their responsibilities to try to systematise the 'learning' process.

We used a list of home care units (71 HHU) provided by the National College of Practitioners (NCP) as an initial sampling frame, but it is not properly updated. However, the Spanish Homecare Society in Spain provided us an updated list of 65 HHUs. Thus, we considered 65 units in this research, attending to the Spanish Homecare Society. Those units were contacted and asked by the Spanish Homecare Society to participate in the study, and 44 agreed. They were also informed by telephone of the work objectives and they were assured of its strictly scientific and confidential character as well as the global and anonymous treatment of the data. Finally, prior to the telephone interviews, a presentation of the study was given at the 8th National Conference on Internal Medicine held on 18th-21st November 2009 in Valencia, Spain.

Surveying took place over a period of two months, from December 2009 to January 2010. Participants were divided into two categories: HHU members with nursing 
backgrounds and HHU members with medical backgrounds. In total, 63 nurse managers and 63 medical managers were telephoned and invited to participate in the study, and a total of 119 questionnaires were collected, of which 3 were found to be without an overall satisfaction rating. Therefore, data analysis was based on 116 valid questionnaires (54 doctors and 62 nurses). The great majority of respondents were female (62.1 percent) and had medical backgrounds (34.7 percent). We did not find a significant difference between the characteristics of HHU members in the sample and those that did not respond to the survey; thus, non-response bias did not seem to be a major concern.

\subsection{Measures}

Churchill's (1979) approach to questionnaire development was used, combining scales from several other relevant empirical studies with new items to make an initial list of 17 items ( 3 measuring the range of the examination of lens fitting; 3 measuring the existence of conditions facilitating the changing of individual habits, 3 measuring the framework for consolidating emergent understandings, 3 measuring the adoption of telemedicine technologies, 2 measuring the diversity of HHUs and 3 relating to quality of service). Several items were modified through interviews with colleagues and a first draft of the questionnaire was tested with three HHUs. Appendix 1 provides an overview of the final questions used in the questionnaire. The questionnaire constructs were as follows:

- We measured the diversity of the HHUs (HD) using a scale of 2 items taken from previous studies (Church \& Zikic, 2004). On one hand, the practitioner's background may impact the level of utilisation for each HHU initiative. In our study, we considered whether (1), the person who answered was a doctor or (2), the person who answered was a nurse. On the other hand, respondents were asked to indicate their gender ( 1 male, 2 female). According to their answers, we found a new variable with a minimum value of two and a maximum value of four, where "2" was "doctor and male" and "4" was "nurse and female".

- As described above, three ideas conform the unlearning context: 'consolidation of emergent understandings', 'the examination of lens fitting', and 'the framework for changing individual habits'. The initial scale comprises nine items taken from a scale designed by Cegarra and Sanchez (2008) to quantify the forgetting context construct. Consequently, the framework for examining the lens fitting (ELF) was measured using three items which recognise the support of policies, rules, reporting, structures and decision-making protocols that encourage the identification of problems, mistakes and new ways of doing things. To measure the process for 'changing individual habits' $(\mathrm{CIH})$, three items were used. This scale focuses on self-awareness issues about our own mistakes, ways of thinking and wrong behaviour that guide our everyday attitudes. The measures relating to the existence of a process for 'consolidating the emergent understandings'(CEU) scale consisted of three items adapted from a scale designed by Akgün, et al. (2007) to quantify the construct of team unlearning. These items describe the way organisational members faced up to change, introduced it actively into the company through projects, collaborated with other members of the organisation, and recognised the value of new information or taking risks. 
- The adoption of telemedicine technology (IT) was measured using a scale of three items taken from previous studies (Hult et al., 2004; Hurley and Hult, 1998). These items recognize support of new technologies that encourage the introduction of services to reduce time that often leads to substantial savings of material and energy in the home care setting.

- For health organisations, performance measures must integrate performance standards and measures designed to monitor the congruency between healthcare delivery processes and patients (Lockamy \& Smith, 2009). The quality of service (QS) fulfils these two objectives - the effective deployment of services requires healthcare practitioners to focus on applying their knowledge to critical healthcare-delivery processes, which in turn influences the patient's perception of satisfaction and value within the health organisation's strategy (Asubonteng et al., 1996). In this paper, we measured perceived quality of service by asking the practitioners to evaluate different aspects of service delivery and outcomes that previous studies have identified (Qureshi \& Rowlands 2004; Francis \& Netten, 2004).

\section{Assessment of the measures}

In order to obtain a robust evaluation of the quality of the seventeen items, a confirmatory analysis (CFA) was achieved using the covariance matrix as input via the EQS 6.1 robust maximum likelihood method (Bentler, 1988). As our model uses reflective indicators of a principal factor latent construct and our data is non-normal, other software packages of structural equation modelling (e.g. LISREL or AMOS) cannot be applied in these circumstances (e.g. Diamantopoulos \& Winklhofer, 2001). The CFA produced a good fit with an incremental fit index (IFI) of 0.944 and a comparative fit index (CFI) of 0.942 (also, Satorra-Bentler $\chi^{2}(104)=142.755 ; \chi^{2} / d . f=$ 1.372; $C F I=0.942 ; I F I=0.944 ; R M S E A=0.056)$.

From an examination of the results shown in Table 1, we can state that all of the constructs are reliable. For all the measures, Bagozzi and Yi's (1988) composite reliability index and Fornell and Larker's (1981) average variance extracted index are higher than the evaluation criteria of 0.7 for composite reliability and 0.5 for the average variance extracted. These results suggest the use of two scales to measure the framework for the HHU's diversity $(A V E=0.615 ; S C R=0.784)$, three scales to measure the framework for examining the lens fitting $(A V E=0.595 ; S C R=0.812)$, three to measure the framework for changing the individual habits $(A V E=0.582, S C R=0.806)$, three items to measure the consolidation of emergent understandings ( $A V E=0.580$, $S C R=0.805)$, three to measure technology slack $(A V E=0.649, S C R=0.847)$ and finally another three to measure quality of service $(A V E=0.649, S C R=0.839)$.

\section{Insert Table 1 about here}

Discriminant validity was determined by calculating the shared variance between pairs of constructs (i.e., the lower triangle of the matrix in Table 2) and verifying that it was lower than the average variances extracted for the individual construct (i.e., the diagonals in Table 2). The shared variances between pairs of all possible scale combinations indicated that the variances extracted were higher than the associated shared variances in all cases (Fornell \& Larcker, 1981). In the interest of thorough 
discriminant validity, an additional test was undertaken, which supports this assumption since the confidence interval ( \pm 2 standard errors) around the correlation estimated between any two latent indicators never includes 1.0 (Anderson \& Gerbing, 1988). The shared variances, means and standard deviations are shown in Table 2.

\section{Insert Table 2 about here}

The unlearning context (UC) was operationalised as a second-order construct with three reflective dimensions (i.e. the three facets of the unlearning context). A second-order confirmatory factor analysis of a model depicting consolidation of emergent understandings, the examination of lens fitting and the framework for changing individual habits was conducted. From an examination of the results shown in Table 3, this model yielded acceptable fit indices (Satorra-Bentler $\chi^{2}(24)=37.481 ; \chi^{2} /$ d. $f=1.561$; $C F I=0.960 ; I F I=0.962 ; R M S E A=0.069)$. In addition, all first-order and second-order factor loadings were significant, thereby providing evidence that UC is a multifaceted construct, construed from consolidation of emergent understandings, the examination of lens fitting and the framework for changing individual habits. Hence, the second-order factor model demonstrated a composite UC in this study.

\section{Insert Table 3 about here}

\section{Results}

Once the psychometric properties of the measures had been checked, the next step was the evaluation of the hypothesised relationships developed from consideration of the relevant literature (see Figure 1), discussed in the text as H1, H2 and H3. The fit of the model is satisfactory (Satorra-Bentler $\chi_{(113)}^{2}=149.915 ; \chi 2 / d . f=1.326 ; C F I=0.945$; $I F I=0.946$; $R M S E A=0.053)$, thereby suggesting that the nomological network of relationships fits our data - another indicator of support for the validity of these scales (Churchill, 1979). With respect to the test of hypothesis $\mathrm{H}_{1}$, our results also support a significant effect of the IT on the QS, with a standardised coefficient of $0.521,(p<0.01)$, thus, these results also provide substantial support for $\mathrm{H}_{1}(I T \rightarrow Q S)$. In testing $\mathrm{H}_{2}$, Figure 1 shows a significant effect of the UC on the IT, with a standardised coefficient of $0.539,(p<0.01)$. With regard to hypothesis $\mathrm{H}_{3}$, Figure 1 shows an insignificant effect of the HD on the IT with a standardised coefficient of 0.108 . This result is worthy of further investigation and this analysis does not provide any support for $\mathrm{H}_{3}$ (i.e. $H D \rightarrow$ IT). One conclusion that might be drawn from this is that there is no group of people with more favourable attitudes to implement telemedicine innovations.

\section{Discussion}

In this time of rapidly changing technology, finding the right solution to implement and use new technologies can present an intricate challenge. As a recent report by PricewaterhouseCoopers noted, half of U.S. consumers are interested in using the Internet, computers and telephone to access homecare services. However, although research shows that many patients are interested in and willing to receive care via telemedicine (e.g. Brecht \& Barrett, 1998; Whitten \& Adams, 2003; Tulu et al., 2007; Lockamy \& Smith, 2009), the results above lead to the expectation that the existing knowledge structures impede the adoption of the telemedicine technologies. Thus, as Rushmer and Davies (2004) noted, when the practitioner relies on inappropriate 
knowledge in providing care services in a home care setting, these sources may hinder the implementation and utilisation of new telemedicine technologies. For example, some physicians share the belief that the use of telemedicine could depersonalise the doctor-patient relationship, add liability issues and potentially lead to medical errors.

This study has examined how an unlearning context can help HHUS get an easier alignment of telemedicine technology and current knowledge structures through an empirical study of 117 HHU members in the Spanish homecare sector. In this regard, despite the fact that high patient satisfaction levels have been reported in the Hospital in the Home programme (see Cleary et al., 1991; Carr-Hill, 1992), the evaluation of the causes of those levels of satisfaction has been underdeveloped. Therefore, the first contribution of this research is to question the existing models which relate to knowledge and homecare quality. This paper suggests that the unlearning context could be a necessary task in the implementation of new telemedicine technologies that is compatible with the current patient demands in innovative situations.

The second contribution of this research derives from the results of the empirical test of the hypotheses. Regarding $\mathrm{H}_{1}$, our results show a bi-directional association between adoption of telemedicine technologies and quality of service. The data indicates that telemedicine technologies provide support to patient responsiveness and action by retaining a broader range of potential responses, thus providing more options for patients when they accede to the variety presented to them by telemedicine technologies. In this regard, Tulu et al. (2007) argue that the Internet is an ideal platform for enhancing transaction efficiencies by streamlining business processes. For example, patients can now easily access databases to offer reliable information about practitioner appointments or prescriptions. The implications of this for quality of service are that telemedicine technologies are useful for the discovery of patient needs in real time and these processes provide knowledge about the wishes and needs of the patients (Brecht \& Barrett, 1998; Whitten \& Adams, 2003; Lockamy \& Smith, 2009). Thus, telemedicine technologies can be seen as an opportunity to enhance the quality of service in HHUs.

With respect to the test of hypothesis $\mathrm{H}_{2}$, our results support that, in order to implement and use new telemedicine technologies, HHUS need to provide and support an unlearning context. Thus, in order to successfully implement new technologies, as well as solving the practitioners' problems, hospital managers need to foster an unlearning context which opens the way for new habits, patterns and ways of doing and interpreting things to take place. This finding corroborates the notions of Rushmer and Davies (2004) that through an unlearning context, organisations foster a capacity for teams and their members to be continuously able to increase their abilities to update and articulate knowledge. That means that not only will the unlearning context support the updating of inappropriate knowledge (Rushmer \& Davies, 2004; Wilson, 1988), but it will also ensure individuals remain at the vanguard in terms of the adoption of new telemedicine technologies rather than being impeded by outdated beliefs (Starbuck, 1996). An unlearning context provides an opportunity for HHU members to 'think outside the box' or to re-examine their habitual, comfortable state of being. Having such an opportunity potentially allows HHU members to change the way they perceive technologies and potentially create and absorb new knowledge. For example, with updated values, procedures, and routines, HHU members will have the advanced tools 
to increase efficiency through automated workflow features or enhance individual achievements through application of new technologies.

In testing $\mathrm{H}_{3}$, our results did not indicate any significant effects of the HHU's diversity on technology use. Although there was a positive association (Figure 2), it was not significant. These results contradict the findings of traditional sociological studies (Dingwall \& McIntosh, 1978; Savage, 1987), and suggest that gender roles have changed, with more female doctors and male nurses in homecare units. Another possible explanation would be the fact that HHU members share their tasks in a collaborative environment. When that happens, doctors and nurses wear many different 'hats' and they may change roles and expand their responsibilities (Fagin \& Garelick, 2004). Under this framework, everybody understands the value of telemedicine technology as a way to simplify tasks and to increase productivity, but this finding also presents evidence to support the belief that HHU members have become more comfortable with technology, removing a stumbling block to opportunities related to technology. Put another way, technology use in a homecare setting has provided equal opportunities for exposure to telemedicine technology for both genders; consequently one would not expect to see gender differences in the way female doctors or male nurses view new technologies.

This study has some limitations. Firstly, it is only able to provide a snapshot of ongoing processes and not measures of the same process over time. Secondly, although the constructs have been defined as precisely as possible by drawing on relevant literature and validated by practitioners, they can realistically only be thought of as proxies for an underlying latent phenomenon that is itself not fully measurable. Thirdly, the model presented in this study was general and did not capture the possible moderating effects of environmental turbulence and uncertainty. Prior research has shown that the effect of cognitive factors on individual, group and organisational performance can vary substantially with environmental conditions. For example, under turbulent conditions, the unlearning context might produce more desirable results for HHUs. Moreover, other factors, which have not been included in this study, are also likely to affect each construct. Taking into account its limitations, this study points to the need for new avenues of research including: the use of additional items to help capture the rich construct to a greater extent; life-cycle effects on the unlearning context; and longitudinal research to further examine the relationships between the unlearning context and the adoption of telemedicine technologies and its impact on quality of service as well. Another possible research direction could examine how patients can contribute to the implementation of the unlearning context. For instance, the patients can provide information about technologies and standardisation issues. HHU members can disclose the problems that they have experienced by using technology, as well as their countermeasures. Another approach, largely unexplored, is to identify flaws in the construction of mental models, and to examine how these flaws contribute to forget right things and learn wrong things.

\section{References}

Akgün, A.E., Byrne, J.C., Lynn, G.S. \& Keskin, H. (2007). Organizational unlearning as changes in beliefs and routines in organizations. Journal of Organizational Change Management, 20(6), 794-812. 
Anderson, J.C. \& Gerbing, D.W. (1988). Structural equation modelling in practice: A review and recommended two-step approach. Psychological Bulletin, 103(3), 411423.

Arch, E. \& Cummins, D. (1989). Structured and unstructured exposure to computers: Sex differences in attitude and use among college students. Sex Roles, 20(5/6), 245254.

Asubonteng, P., McCleary, K.J. \& Swan, J.E. (1996). SERVQUAL Revisited: A Critical Review of Service Quality. The Journal of Services Marketing, 10(6), 6281.

Bagozzi, R.P. \& Yi, Y. (1988). On the evaluation of structural equation models. Journal of the Academy of Marketing Science, 16(1), 7494.

Barlow, J. \& Hendy, J. (2009). Adopting integrated mainstream telecare services Lessons from the UK. Eurohealth, 15(1), 8-10.

Bentler, P. (1988). Practical issues in structural modeling, in Long, J.S. (Ed.), Common Problems/Proper Solutions: Avoiding Error in Quantitative Research, Sage Publications, Newbury Park, CA, pp. 161-92.

Berg, M. (2001). Health information management: integrating information technology in health care work. London: Routledge.

Bettis, R. A. \& Prahalad, C. K. (1995). The dominant logic: Retrospective and extension, Strategic Management Journal, 16, 5-14.

Bhatt, G., Gupta, J. N.D.,\& Kitchens, F. (2005) An exploratory study of groupware use in the knowledge management process, Journal of Enterprise Information Management, 18 (1), 28 - 46

Brailer, D., \& Thompson, T. (2004). Health IT strategic framework. Washington, DC: Department of Health and Human Services.

Brakensiek, J.C. (2002). Knowledge management for EHS professionals. Occupational Health \& Safety, 71(1), 72-74.

Brecht, R.M. \& Barrett, J.E. (1998). Telemedicine in the United States, in Viegas, S.F., Dunn, K. (Eds),Telemedicine Practicing in the Information Age, Lippencott-Raven Publishers, Philadelphia, PA, pp.25-30.

Carr-Hill, R. (1992). The measurement of patient satisfaction. Journal Public Health Medicine, 14(3), 236-249.

Cegarra, J,G. \& Cepeda, G. (2010). How to implement a knowledge management program in hospital-in-the-home units. Leadership in Health Services, 23(1), 46-56.

Cegarra, J.G. \& Sánchez, M.T. (2008). Linking the individual forgetting context with customer capital from a seller's perspective. Journal of the Operational Research Society, 59(12), 1614-1623.

Chaudhry, B. Wang , J., \& Wu, S. et al., (2006). Systematic review: Impact of health information technology on quality, efficiency, and costs of medical care. Annals of Internal Medicine, 144(10), 742-752.

Church, R. \& Zikic, J. (2004). Organizational culture, group diversity and intra-group conflict. Team Performance Management, 10(1/2), 26-34.

Churchill, G.A. (1979). A paradigm for developing better measures for marketing constructs. Journal of Marketing Research, 16(1), 64-73.

Cleary, P., Edgman-Levitan, S. \& Roberts, M. (1991). Patients evaluate their hospital care. Health Affairs, 10(4), 254-267.

Day, G.S. \& Nedungandi, P. (1994), Managerial representations of competitive advantage. Journal of Marketing, 58(2), 31-44.

De Holan, P. \& Philps, N. (2004). The remembrance of things past? The dynamics of organizational forgetting, Management Science, 50, 1603-1613. 
Diamantopoulos, A. \& Winklhofer, H. (2001). Index construction with formative indicators: An alternative to scale development. Journal of Marketing Research, 38(2), 269-277.

Dingwall, R. \& McIntosh, J. (eds) (1978). Readings in the Sociology of Nursing. Edinburgh: Churchill Livingstone.

Fagin, L. \& Garelick, A. (2004). The doctor-nurse relationship. Advances in Psychiatric Treatment, 10, 277-286.

Fenwick, T. (2007) Knowledge workers in the in-between: network identities. Journal of Organizational Change Management, 20(4), 509-524.

Fornell, C. \& Larcker, D.F. (1981). Evaluating structural equation models with unobservable variables and measurement error. Journal of Marketing Research, 18(1), 39-50.

Francis, J. \& Netten, A. (2004). Raising the Quality of Home Care: A Study of Service Users' Views. Social policy and administration, 38(3), 290-305.

Gagnon MP, Lamothe L, Fortin JP, Cloutier A, Godin G, Gagné C, Reinharz D. (2005). Telehealth adoption in hospitals: an organisational perspective. Journal of Health Organization and Management, 19(1), 32- 56.

Harrington, S.J. \& Guimaraes, T. (2005). Corporate Culture, Absorptive Capacity and IT Success. Information and Organization, 15(1), 39-63.

Hult, G. T. M., Hurley, R. F. \& Knight, G. A. (2004). Innovativeness: Its antecedents and impact on business performance, Industrial Marketing Management, 33, 429438.

Hurley, R. E. \& Hult, G. T. M. (1998). Innovation, market orientation and organizational learning: An integration and empirical examination, Journal of Marketing, 62, 42-54.

Jones-Devitt, S. \& Smith, L. (2007). Critical Thinking in Health and Social Care, Sage Publications Ltd; London.

Lapointe, L. \& Rivard, S. (2005). A multilevel model of resistance to information technology implementation. MIS Quaterly, 29(3), 461-491,

Lockamy, A. \& Smith, D. (2009). Telemedicine: a process enabler for enhanced healthcare delivery systems. Business Process Management Journal, 15(1), 5-19.

Menachemi, N., Chukmaitov, A., Saunders, C. \& Brooks, R.G. (2008). Hospital quality of care: Does information technology matter? The relationship between information technology adoption and quality of care. Health Care Management Review, 33(1), 51-59.

Montalto M. (1996). Patients' and careers's satisfaction with Hospital-in-the-Home Care. International Journal for Quality in Health Care, 8(3), 243-251.

Morikawa, M. (2004). Information Technology and the Performance of Japanese SMEs. Small Business Economics, 23(3), 171-177.

Mort, M., May, C.R. \& Williams, T. (2003). Remote doctors and absent patients: Acting at a distance in telemedicine? Science, Technology, and Human Values, 28(2), 274-296.

Navarro, V. (2000). Assessment of the World Health Report. The Lancet, 356(9241), 1598-1601.

Nonaka, I. \& Takeuchi, H. (1995). The knowledge-creating company. How Japanese companies create the dynamics of innovation. Oxford University Press, New York.

Qureshi, H. \& Rowlands, O. (2004). User Satisfaction Surveys and Cognitive Question Testing in the Public Sector: The Case of Personal Social Services in England. International journal of social research methodology, 7(4), 273-288. 
Ridao, M., Peiró, S., Marchan, C. (1997). Hospitalización a domicilio y hospitalización convencional: una evaluación económica. Medicina Clínica, 109, 207-211.

Rushmer, R. \& Davies, H.T. (2004). Unlearning in health care. Quality Safety Health Care, 13, 10-15.

Satorra, A. \& Bentler, P.M. (1988). Scaling corrections for chi-square statistics in covariance structure analysis. In: American Statistical Association (Ed.), In Proceedings of the business and economic statistics section. Alexandria, VA: American Statistical Association, pp. 308-313.

Savage, J. (1987). Nurses and Gender. Milton Keynes: Open University Press.

Shaw, R.B. \& Perkins, D.N. (1991). Teaching organizations to learn. Organization Development Journal, 9(4), 1-12.

Sorensen, C. \& U. Lundh-Snis (2001). Innovation through knowledge codification. Journal of Information Technology, 16(2), 83-97.

Stanberry, B. (2000). Telemedicine: barriers and opportunities in the 21 st century. Journal of Internal Medicine, 247(6), 615-628.

Starbuck, W.H. (1996). Unlearning ineffective or obsolete technologies. International Journal of Technology Management, 11(3), 725-737.

Thouin, M.F., Hoffman, J.J. \& Ford, E.W. (2008). The effect of information technology investment on firm-level performance in the health care industry. Health Care Management Review, 33(1), 60-68.

Tulu, B., Chatterjee, S. \& Maheshwari, M. (2007). Telemedicine taxonomy: A classification tool. Telemedicine and e-Health, 13(3), 349-358.

Whitten, P. \& Adams, I. (2003). Success and failure: a case study of two rural telemedicine projects. Journal of Telemedicine and Telecare, 9(3), 125-129.

Wilson, D.G. (1988). The invaluable art of unlearning. Journal of the Royal Society of Medicine, 81(3), 3-6.

Winthereik, B.R. \& Bansler. J.P. (2007). Connecting Practices: ICT Infrastructures to Support Integrated Care. International Journal of Integrated Care, 7, e16. 


\section{Appendix 1: Questionnaire items}

The consolidation of emergent understandings: with respect to your organisation indicate the degree of agreement or disagreement $(1=$ high disagreement and $7=$ high agreement $)$ :

CEU_1: Managers adopt the suggestions of personnel in the form of new routines and processes

CEU_2: Managers are prone to collaborate with members of the organisation and to solve problems together

CEU_3: Managers are concerned with the fact that the manner of answering before unforeseen circumstances will be known by all

(Source: Cegarra \& Sánchez, 2008)

The examination of lens fitting: with respect to your current position indicate the degree of agreement or disagreement ( $1=$ high disagreement and $7=$ high agreement $)$ :

ELF_1: Employees are able to listen to their customers (e.g. complaints, suggestions)

ELF_2: Employees are able to share information with their boss easily

ELF_3: Employees try to reflect and learn from their own mistakes

(Source: Cegarra \& Sánchez, 2008)

The framework for changing individual habits: with respect to your personal skills, indicate the degree of agreement or disagreement ( $1=$ high disagreement and $7=$ high agreement):

CIH_1: New situations have helped individuals change their thoughts

CIH_2: New situations have helped individuals recognise undesirable attitudes

CIH_3: New situations have helped individuals change their attitudes

(Source: Cegarra \& Sánchez, 2008)

Adoption of telemedicine technology: with respect to other homecare units, indicate the degree in which your unit reached the following objectives in the last three years $(1=$ not reached at all and $7=$ reached well).

IT_1: The introduction of new technology services in the practice of homecare

IT_2: The introduction of new technology in the practice of homecare

IT_3: The rate of technological innovation

(Source: adopted from Hult et al., 2004; Hurley and Hult, 1998)

Quality of service: with respect to the hospital's other medical services, indicate the degree in which your unit reached the following objectives $(1=$ not reached at all and $7=$ reached well $)$.

QS_1: Quality of services

QS_2: A more efficient use of resources

QS_3: Satisfaction of patients

(Source: adapted from Qureshi \& Rowlands 2004; Francis \& Netten, 2004) 
Table: 1. Factor loadings of the resulting items and scale reliability

\begin{tabular}{|c|c|c|c|c|}
\hline Construct & & $\begin{array}{c}\text { Standardized } \\
\text { loading }\end{array}$ & t-value & $\begin{array}{c}\text { Reliability } \\
\left(\text { SCR }^{\mathbf{a}} \text {., } \text { AVE }^{\mathbf{b}}\right)\end{array}$ \\
\hline \multicolumn{5}{|l|}{ Diversity of the HHU (HD) } \\
\hline \multirow{2}{*}{\multicolumn{2}{|c|}{$\begin{array}{l}\text { The practitioner's background } \\
\text { Gender }\end{array}$}} & 0,729 & 2.714 & $\mathrm{AVE}=0.615$ \\
\hline & & 0,410 & 2.427 & $\mathrm{SCR}=0.784$ \\
\hline \multicolumn{5}{|c|}{ The consolidation of emergent understandings (CEU) } \\
\hline & CEU_1 & 0,897 & 7.538 & \multirow{3}{*}{$\begin{array}{l}\mathrm{AVE}=0.580 \\
\mathrm{SCR}=0.805\end{array}$} \\
\hline & CEU_2 & 0,931 & 9.697 & \\
\hline & CEU_3 & 0,818 & 7.400 & \\
\hline \multicolumn{5}{|c|}{ The framework for the examination of lens fitting (ELF) } \\
\hline & ELF_1 & 0,691 & 5.027 & \multirow{3}{*}{$\begin{array}{l}\mathrm{AVE}=0.595 \\
\mathrm{SCR}=0.812\end{array}$} \\
\hline & ELF_2 & 0,895 & 9.126 & \\
\hline & ELF_3 & 0,954 & 9.963 & \\
\hline \multicolumn{5}{|c|}{ The framework for changing the individual habits (CIH) } \\
\hline & CIH_1 & 0,929 & 11.500 & \multirow{3}{*}{$\begin{array}{l}\mathrm{AVE}=0.582 \\
\mathrm{SCR}=0.806\end{array}$} \\
\hline & CIH_2 & 0,911 & 11.245 & \\
\hline & CIH_3 & 0,791 & 8.042 & \\
\hline \multicolumn{5}{|c|}{ Adoption of telemedicine technology(IT) } \\
\hline & IT_1 & 0,787 & 8.514 & \multirow{3}{*}{$\begin{aligned} \mathrm{AVE} & =0.649 \\
\mathrm{SCR} & =0.847\end{aligned}$} \\
\hline & IT_2 & 0,762 & 8.338 & \\
\hline & IT_3 & 0,810 & 11.034 & \\
\hline \multicolumn{5}{|l|}{ Quality of service (QS) } \\
\hline & QS_1 & 0,921 & 10.644 & \multirow{3}{*}{$\begin{array}{l}\mathrm{AVE}=0.649 \\
\mathrm{SCR}=0.839\end{array}$} \\
\hline & QS_2 & 0,833 & 10.274 & \\
\hline & QS 3 & 0,483 & 4.277 & \\
\hline
\end{tabular}

Notes:

The fit statistics for the measurement model were:

Satorra-Bentler $\chi^{2}{ }_{(104)}=142.755 ; \chi^{2} / \mathrm{d} . \mathrm{f}=1.372 ; \mathrm{CFI}=0.942 ; \mathrm{IFI}=0.944 ; \mathrm{RMSEA}=0.056$

${ }^{a}$ Scale Composite Reliability (SCR) of $\mathrm{p}_{\mathrm{c}}=\left(\Sigma \lambda_{\mathrm{i}}\right)^{2} \operatorname{var}(\xi) /\left[\left(\Sigma \lambda_{\mathrm{i}}\right)^{2} \operatorname{var}(\xi)+\Sigma \theta_{\mathrm{ii}}\right]$ (Bagozzi and Yi, 1998).

${ }^{\mathrm{b}}$ Average variance extracted $(\mathrm{AVE})$ of $\mathrm{p}_{\mathrm{c}}=\left(\sum \lambda \mathrm{i} 2 \operatorname{var}(\xi)\right) /\left[\sum \lambda \mathrm{i}^{2} \operatorname{var}(\xi)+\sum \theta \mathrm{ii}\right]$ (Fornell and Larcker, 1981).

The asymptotic covariance matrices were generated to obtain the scaled chi-square (Satorra and Bentler, 1988) and robust estimation of standard errors. 
Table 2 Descriptive statistics and discriminant validity

\begin{tabular}{lcccccccc}
\hline & Mean & S.D & $\mathbf{1}$ & $\mathbf{2}$ & $\mathbf{3}$ & $\mathbf{4}$ & $\mathbf{5}$ & $\mathbf{6}$ \\
\hline 1. Diversity of the HHU & 1.579 & 0.400 & $\mathbf{0 . 7 8 4}$ & & & & & \\
2. Consolidation of understandings & 5.692 & 1.152 & 0.004 & $\mathbf{0 . 7 6 1}$ & & & \\
3. Examination of lens fitting & 6.219 & 0.816 & 0.023 & 0.318 & $\mathbf{0 . 7 7 1}$ & & \\
4. Changing the individual habits & 5.448 & 1.016 & 0.020 & 0.437 & 0.195 & $\mathbf{0 . 7 6 2}$ & \\
5. Adoption of telemedicine technology & 4.319 & 1.464 & 0.003 & 0.218 & 0.053 & 0.181 & $\mathbf{0 . 8 0 5}$ & \\
6. Quality of service & 5.808 & 0.910 & 0.015 & 0.203 & 0.089 & 0.066 & 0.243 & $\mathbf{0 . 8 0 5}$ \\
\hline
\end{tabular}

\section{Notes:}

Mean $=$ the average score for all of the items included in this measure; S.D. = Standard Deviation; AVE =

Average Variance Extracted; the bold numbers on the diagonal are the square root of the Average Variance Extracted, Shared variances are given in the lower triangle of the matrix. 
Table 3 Second-order confirmatory factor analysis of the unlearning context

\begin{tabular}{|lccccc|}
\hline \multicolumn{1}{c}{ First-order construct } & \multicolumn{2}{c}{ First-order } & \multicolumn{2}{c}{ Second-order } \\
\hline Framework for & Indicator & Loading & $t$-value & Loading & $t$-value \\
consolidating the emergent & $\mathrm{Y}_{7}$ & 0.892 & -a & & \\
understandings (CEU) & $\mathrm{Y}_{8}$ & 0.934 & 8.496 & 0.916 & 5.873 \\
\hline \multirow{2}{*}{ Framework for } & $\mathrm{Y}_{9}$ & 0.822 & 9.557 & & \\
examining the lens fitting (ELF) & $\mathrm{Y}_{1}$ & 0.691 & -a & & \\
& $\mathrm{Y}_{2}$ & 0.893 & 5.948 & 0.612 & 3.828 \\
\hline \multirow{2}{*}{ Framework for changing the } & $\mathrm{Y}_{3}$ & 0.856 & 6.208 & & \\
individual habits (CIH) & $\mathrm{Y}_{4}$ & 0.928 & $-\mathrm{a}$ & & \\
& $\mathrm{Y}_{5}$ & 0.914 & 13.124 & 0.720 & 6.710 \\
\hline
\end{tabular}

Notes:

Fit statistics for measurement model of 9 indicators for three constructs:

Satorra-Bentler $\chi^{2}(24)=37.481 ; \chi^{2} /$ d.f $=1.561 ; \mathrm{CFI}=0.960 ; \mathrm{IFI}=0.962 ; \mathrm{RMSEA}=0.069$.

${ }^{\text {a }}$ Fixed parameter. 
Figure 1: Conceptual model

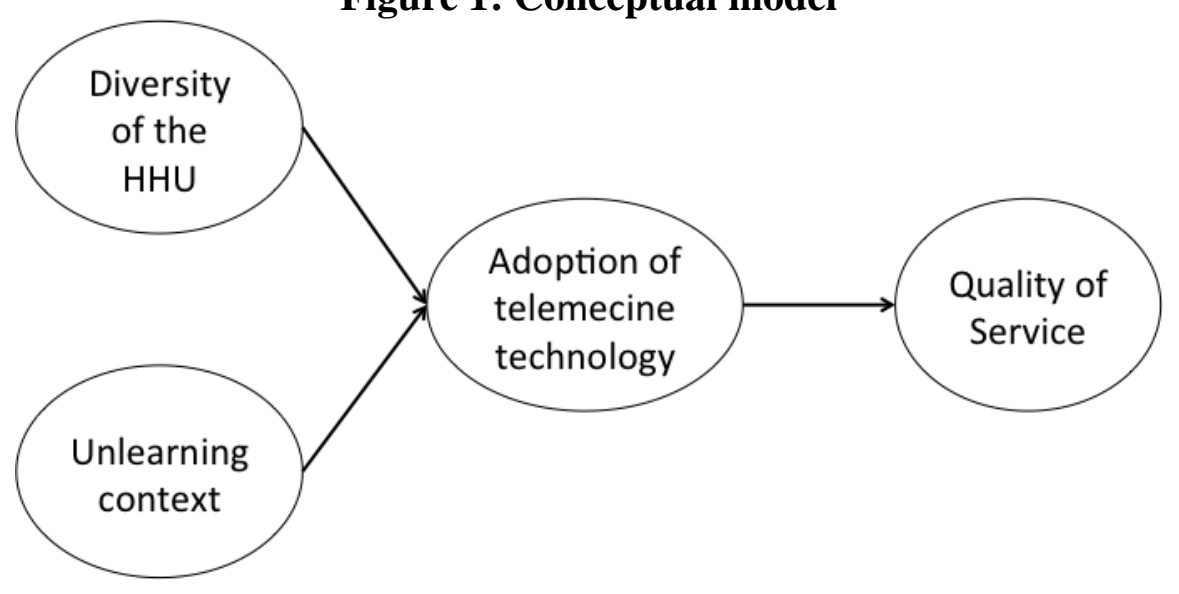


Figure 2: Model statistics

Notes:

The fit statistics for the measurement model were:

Satorra-Bentler $\chi 2_{(113)}=149.915 ; \chi 2 /$ d.f $=1.326 ; \mathrm{CFI}=0.945 ; \mathrm{IFI}=0.946 ; \mathrm{RMSEA}=0.053$

$* * * \mathrm{p}<0.01$ 